Article

\title{
Femtosecond Laser Nano/Micro Textured Ti6A14V Surfaces-Effect on Wetting and MG-63 Cell Adhesion
}

\author{
Georg Schnell ${ }^{1, *}$, Susanne Staehlke ${ }^{2}$, Ulrike Duenow ${ }^{1}$, J. Barbara Nebe ${ }^{2,3}{ }^{\mathbb{D}}$ and \\ Hermann Seitz ${ }^{1,3}$ (D) \\ 1 Microfluidics, Faculty of Mechanical Engineering and Marine Technology, University of Rostock, \\ Justus-von-Liebig Weg 6, 18059 Rostock, Germany \\ 2 Deptartment of Cell Biology, University Medical Center Rostock, Schillingallee 69, 18057 Rostock, Germany \\ 3 Deptartment Life, Light \& Matter, University of Rostock, Albert-Einstein-Str. 25, 18059 Rostock, Germany \\ * Correspondence: georg.schnell@uni-rostock.de; Tel.: +49-381-498-9093
}

Received: 24 May 2019; Accepted: 5 July 2019; Published: 9 July 2019

\begin{abstract}
Nano- and microstructured titanium surfaces have recently attracted attention in the field of regenerative medicine because of the influence which surface characteristics such as roughness and wettability can have on cellular processes. This study focuses on the correlation of surface properties (wettability and nano/micro texture) of laser-structured Ti6Al4V samples with pronounced cell adhesion. Samples were structured with multiple laser parameters in order to create a range of surface properties. Surface characterization was performed by contact angle measurements 1 and 7 days after laser processing. The arithmetic mean roughness of the material surface in an area (Sa) was determined by means of confocal laser scanning microscopy (CLSM). Immediately after wettability tests of the laser-structured surfaces, in vitro experiments with human MG-63 osteoblasts were carried out. For this purpose, the cell morphology and actin cytoskeleton organization were analyzed using CLSM and scanning electron microscopy. On rough microstructures with deep cavities, the cell growth and spreading were inhibited. An improved cellular adhesion and growth on nanostructured and sinusoidal microstructured surfaces could be demonstrated, regardless of hydrophilicity of the surfaces.
\end{abstract}

Keywords: Ti6Al4V; femtosecond laser; microstructure; osteoblasts; morphology; actin cytoskeleton

\section{Introduction}

The modification and optimization of the surface properties of implants with a focus on cell adhesion was investigated by many research groups [1-4]. Titanium and titanium alloys are widely used as biomaterial for implants due to their high biocompatibility [5,6]. Specifically, Ti6Al4V material is used for bone implants [7,8], as hip and knee joints, dental and jaw implants, and generally in reconstructive surgery. Surface modification strategies are used to induce bone healing process and osseointegration capability [9].

The laser structuring of Ti6Al4V samples is of particular interest for a multitude of biomedical applications [10]. Due to the high reproducibility, flexibility, and capability of generating a wide range of surface structures, femtosecond laser irradiation is a highly attractive manufacturing method to vary the wetting properties $[11,12]$ or cell behavior patterns $[13,14]$. Therefore, the structuring of separate areas of the implant surface can be used to cause desired and particular cell behavior $[15,16]$. It can also provide an improved bone-implant interface anchorage [17] or the reduction of bacterial adhesion and biofilm formation $[18,19]$. 
It is known that surface characteristics such as roughness and wettability influence cellular processes like spreading, proliferation, differentiation, and intracellular signaling via $\mathrm{Ca}^{2+}$ ions $[2,3,15]$. Often a hydrophilic wetting state of surfaces is associated with an increase of bone formation in the peri-implant region in comparison to hydrophobic surfaces [4]. However, especially on laser structured metallic surfaces, a strong change of the wetting state over time is observed $[11,20]$ and the correlation between hydrophilicity and pronounced cell adhesion is put into question [21]. In summary, the effect of a changed wetting state on cell behavior is unclear and the significance of the correlation between hydrophilicity and pronounced cell adhesion should therefore be analyzed. The aim of this study is to investigate the adhesion, morphology, and growth of human osteoblasts on femtosecond laser produced nano- and microstructured surfaces dependent on the wetting state over time.

\section{Materials and Methods}

\subsection{Materials and Sample Pretreatment}

The experimental investigations were carried out with Ti6Al4V samples $(1 \times 1 \mathrm{~cm})$. Water-jet cut plates were purchased from $\mathrm{S}+\mathrm{D}$ Spezialstahl Handelsgesellschaft $\mathrm{mbH}$ (Stelle, Germany). The specification complies with the requirements of AMS4911 [22] and WL 3.7164 Part 1 [23]. For a consistent and fine roughness of the surface, the plates were polished with silicon carbide abrasive sandpaper from P320 ( $\mathrm{t} 1=4 \mathrm{~min}), \mathrm{P} 600(\mathrm{t} 2=4 \mathrm{~min})$ to P1200 ( $\mathrm{t} 3=8 \mathrm{~min}$ ) grain size and certain periods and under ultrapure water (Reference). The abrasive treatment was followed by a cleaning in an ultrasonic bath Sonorex Super RK 100/K (Bandelin electronic GmbH\&Co.KG, Berlin, Germany) with ultrapure water for $10 \mathrm{~min}$. Drying was performed with dust free cloth and compressed air.

\subsection{Micromachining}

For laser structuring of Ti6Al4V, the femtosecond fiber laser of the type UFFL_60_200_1030_350_SHG of the manufacturer Active Fiber Systems GmbH (Jena, Germany) was used. It is a fiber laser with an amorphous glass with an $\mathrm{Yb}$-doped core. The wavelength used was $1030 \mathrm{~nm}$ with linear polarized light and the pulse duration was $300 \mathrm{fs}$. For deflecting the laser beam, a scanner system of the type intelliSCANse (Scanlab GmbH, Puchheim, Germany) was used. The beam was focused by an F-theta lens with a focal length of $163 \mathrm{~mm}$ resulting in a beam spot diameter of about 36 microns. The laser system enables a repetition rate from $50.3 \mathrm{kHz}$ up to $18.6 \mathrm{MHz}$ up to an average power of $60 \mathrm{~W}$. The laser is integrated in the micromachining device Microgantry GU4 (Kugler, Salem, Germany). To create widely different femtosecond laser-induced periodic structures (FLIPPS1 and FLIPPS2) and microstructures (Micro1 and Micro2) with various roughness, the laser parameters were varied in pulse energy, line overlap and procedure of laser passage (line and grid), as shown in Table 1 . The pulse overlap was kept constant at 50\% and number of overscans was 50 . For each structure, two specimens were manufactured. Samples without micromachining were used as references (plane Ti6Al4V specimen).

Table 1. Laser parameter settings and procedure of laser scanning.

\begin{tabular}{ccccc}
\hline Structure & \multicolumn{3}{c}{ Laser Parameters } \\
\hline & Pulse Energy $(\mu \mathrm{J})$ & Fluence in Focus $\left(\mathbf{J} / \mathrm{cm}^{2}\right)$ & Line Overlap $\mathbf{( \% )}$ & Procedure of Laser Passages \\
\hline Micro1 & 50 & 9.82 & 60 & Grid \\
Micro2 & 50 & 9.82 & 30 & Grid \\
FLIPSS1 & 15 & 2.95 & 90 & Line \\
FLIPSS2 & 5 & 0.98 & 80 & Grid \\
\hline
\end{tabular}

\subsection{Surface Characterization}

The average area surface roughness (Sa) and the elevation profile (depth and width of the resulting pillars and profiles, respectively) were determined by means of a confocal laser scanning 
microscope (CLSM) of the type LEXT OLS 4000 (Olympus, Hamburg, Germany) for every sample three times at random areas. A constant optical magnification $(50 \times)$ was utilized leading to a scan area of $256 \times 256 \mu \mathrm{m}$. The resulting scans have a resolution of 1024 by 1024 pixels. The software OLS4000 (Olympus, Hamburg, Germany) was used for data calculation and visualization. For detailed images, a scanning electron microscope (SEM) StereoScan360 (Cambridge Instruments, Cambridge, UK) was used.

\subsection{Wetting Properties}

To determine the resulting contact angle of the investigated surfaces after 1 and 7 days, a computer-controlled contact angle meter OCA 40 Micro (DataPhysics Instruments GmbH, Filderstadt, Germany) was used. The drop volume of distilled water was adjusted to $5 \mu \mathrm{L}$ at a dosage rate of $1 \mu \mathrm{L} / \mathrm{s}$. For each surface and time, the contact angle was measured three times.

\subsection{Cell Culture}

To study the cell adhesion, morphology, and growth on laser-structured surfaces compared to the reference, the human osteoblast cell line MG-63 (ATCC ${ }^{\circledR}$ American Type Culture Collection CRL-1427 ${ }^{\mathrm{TM}}$, Manassas, VA, USA) was used. In our previous work we could demonstrate that cell adhesion, spreading, and proliferation were stable over passages 5-30, and were similar to human primary osteoblasts [24]. The MG-63 osteoblasts were cultured in Dulbecco's modified Eagle's medium (DMEM) with 10\% fetal calf serum (both Merck, Darmstadt, Germany) and 1\% gentamicin (Ratiopharm GmbH, Ulm, Germany) at $37^{\circ} \mathrm{C}$ and $5 \% \mathrm{CO}_{2}$ atmosphere (incubator, SANYO CO2 INKUBATOR MCO-18AIC-UV, Panasonic Biomedical, Osaka, Japan). For the study, laser-structured and planar reference Ti6Al4V surfaces were exposed to cell culture immediately after wettability characterizations ( 1 and 7 days). The osteoblasts were seeded onto the samples $(1 \times 1 \mathrm{~cm})$ at a density of 30,000 cells for $24 \mathrm{~h}$.

\subsection{Morphology and Spreading of MG-63 Cells}

The morphology of MG-63 osteoblasts was analyzed by field emission scanning electron microscopy (FE-SEM, 5 kV; Merlin VP compact, Carl Zeiss, Oberkochen, Germany). The cells were fixed with $2.5 \%$ glutaraldehyde (Merck), dehydrated through a grade series of ethanol $(30 \%, 50 \%$, $75 \%, 90 \%, 100 \%$ ), and dried in K850 critical point dryer (Emitech, Taunusstein, Germany). As the final step, cells were sputtered with a $20 \mathrm{~nm}$ gold-layer (SCD 004, BAL-TEC, Balzers, Liechtenstein, Liechtenstein). To image the cells, a high efficiency secondary electron detector (HE-SE) was used.

The cell spreading was analyzed by using ImageJ (Version 1.51f, Wayne Rasband, National Institutes of Health, Bethesda, MD, USA) of the FS-SEM images. For this, 40 cell areas per sample were calculated, and the statistical analyses were performed with GraphPad Prism (Version 7.02, GraphPad Software Inc., La Jolla, CA, USA) by non-parametric Kruskal-Wallis test post hoc uncorrected Dunn's test (analysis of variance) $\left({ }^{*} p<0.001\right)$. The data were presented as mean \pm standard error of the mean (s.e.m.).

\subsection{Actin Cytoskeleton Organization}

The actin cytoskeleton organization of MG-63 cells was conducted by confocal laser scanning microscopy (CLSM) (LSM780, Carl Zeiss Microscopy GmbH, Jena, Germany) with helium-neon laser (excitation: $543 \mathrm{~nm}$ ), and $40 \times$ water objective. Cells were fixed with $10 \%$ paraformaldehyde (PFA, Merck KGaA, Darmstadt, Germany), permeabilized with $0.1 \%$ Triton X-100 (4-(1,1,3,3-Tetramethylbutyl)phenyl-polyethylene glycol, Merck KGaA, Darmstadt, Germany) and incubated with phalloidin TRITC (phalloidin-tetramethyl-rhodamine, 1:7, Sigma-Aldrich, St. Louis, MO, USA). Next, the samples were embedded in Fluoroshield ${ }^{\mathrm{TM}}$ with DAPI (4' ${ }^{\prime}$ 6-Diamidin-2-phenylindol, DAPI, Sigma-Aldrich, St. Louis, MO, USA) on a cover slip and stored in the dark at $4{ }^{\circ} \mathrm{C}$. For image acquisition, the ZEN 2011 software (ZEISS Efficient Navigation, ZEN 2011 SP4, black edition, Carl Zeiss, Carl Zeiss Microscopy GmbH, Jena, Germany) was used. 
Furthermore, to obtain quantitative information of cytoskeletal organization, the actin filament number, length, and orientation were analyzed by using FilaQuant software (Institute of Mathematics, Mathematical Optimization, University of Rostock, Rostock, Germany) based on confocal images [25,26]. The mathematical image processing was completed for 10 cells per sample, and statistical evaluation was done using GraphPad Prism (Version 7.02, GraphPad Software Inc., La Jolla, CA, USA) by parametric ANOVA post hoc Bonferroni (analysis of variance) $\left({ }^{*} p>0.05\right)$. The results were presented as mean \pm s.e.m.

\section{Results and Discussion}

\subsection{Surface Characterization}

The SEM images with related CLSM images and elevation profile are shown in Figure 1. Generally, three types of structures can be observed: Stochastic pillared microstructures (Micro1), sinusoids periodic microstructures (Micro2) and nanostructures (FLIPSS1 and FLIPSS2). Under laser irradiation at 5 and $15 \mu \mathrm{J}$, femtosecond laser-induced periodic structures (FLIPSS) are formed with a corresponding periodicity close to the laser wavelength $(\lambda=1030 \mathrm{~nm})$. It is widely understood that the formation of these structures is caused by interferences between linearly polarized laser light and excited surface plasmon polaritons and orientated perpendicular to the polarization vector of the incident light [27]. Fluences are slightly higher than the ablation threshold resulting in a generation of laser-induced periodic structures (LIPSS).

(a)
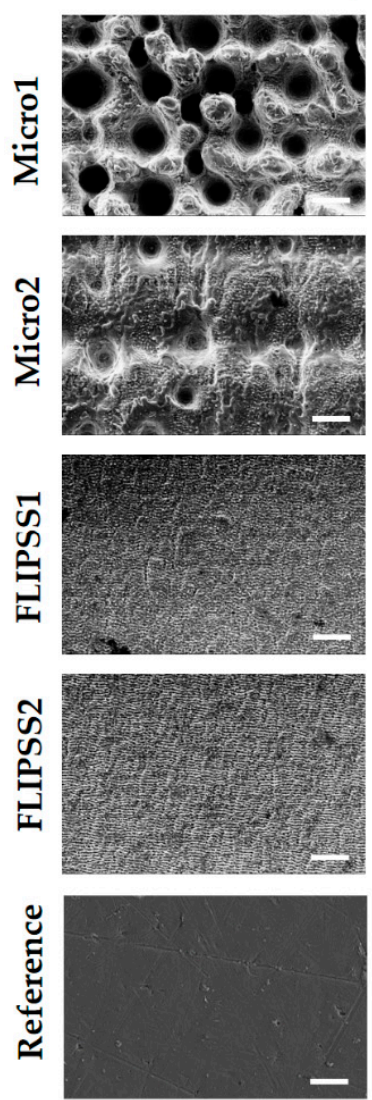
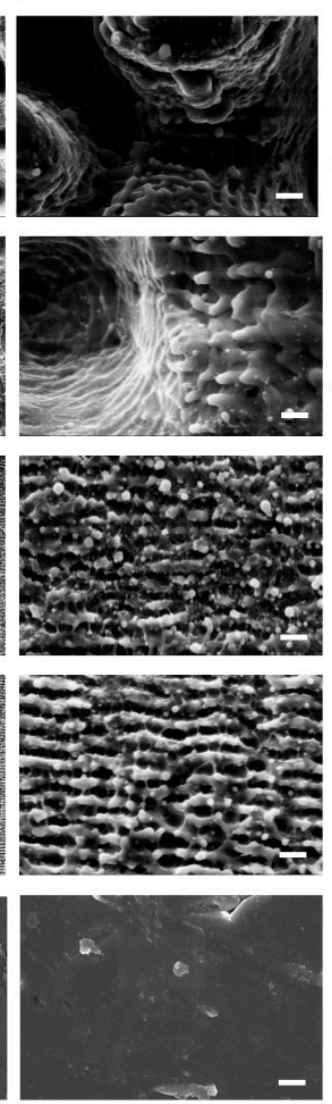
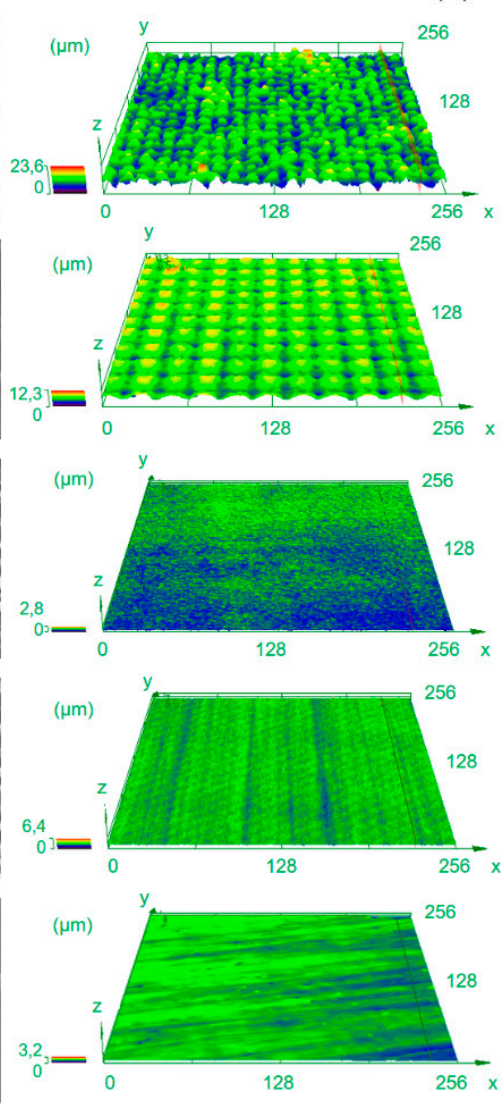

(b)
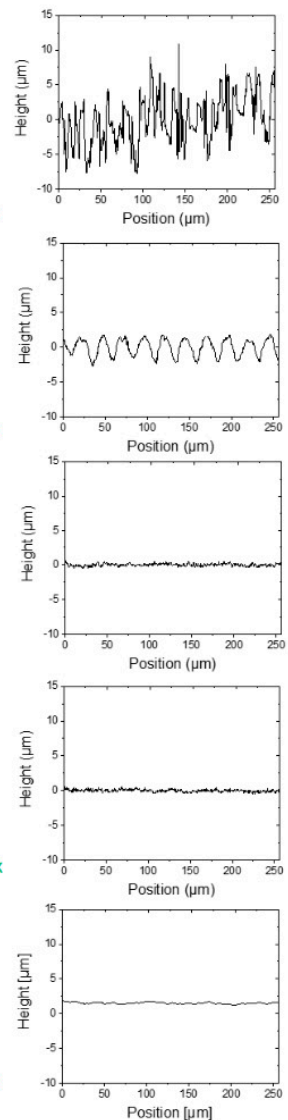

Figure 1. Surface characterization of laser-structured Ti6Al4V specimens. (a) Scanning electron microscope images (StereoScan360), scale bars left: $10 \mu \mathrm{m}$, right: $1 \mu \mathrm{m}$ and (b) confocal laser scanning microscope images (LEXT OLS 4000), square side length: $256 \mu \mathrm{m}$, with corresponding elevation profile of laser irradiated structures and polished Ti6Al4V reference. 
The resulting surface roughnesses (Sa) are shown in Table 2. It can be seen that the roughness varies in a range from $\mathrm{Sa}=0.13 \mu \mathrm{m}$ to a maximum roughness of $2.96 \mu \mathrm{m}$. The roughness $\mathrm{Sa}$ of the structures FLIPPS1 and FLIPPS2 are nearly the same or marginally higher than the roughness of the untreated reference. The small increase of Sa of the FLIPSS structures in relation to the reference is a result of the higher periodicity of the micro elevations, since the average height of the samples is almost similar. With increased pulse energy, microstructures with dual scale roughness are formed. Micro1 are stochastic structures due to high line overlap, Micro2 are sinusoids periodic structures caused by small line overlap from laser treatment. The formation of stochastic structures like Micro1 is discussed widely and attributed to different mechanisms. Thus, for example, hydrodynamic effects [28], varying ablation threshold through inhomogeneous element distribution or impurities in the surface of the material or inconsistent flow of the surface melt from previous irradiations appears to be responsible for the formation of these structures [29]. Figure 1 reveals that Micro2 structures are covered with more nanostructures than Micro1. FLIPPS are also created at higher pulse energies, since the fluence by a Gaussian laser beam decreases from the center to the edge of the irradiated area [30]. Due to the lower line overlap at similar number of overscans, FLIPPS are more extended on Micro2, because more area is primary irradiated with fluences slightly above the ablation threshold.

Table 2. Average area surface roughness Sa and surface micro-profile of laser-structured surfaces and reference. The values are listed separately for each specimen.

\begin{tabular}{cccc}
\hline \multirow{2}{*}{ Sample } & Roughness & \multicolumn{2}{c}{ Pillar/Profile Dimension } \\
\cline { 2 - 4 } & Sa $(\mu \mathrm{m})$ & Depth $(\mu \mathrm{m})$ & Width $(\mu \mathrm{m})$ \\
\hline \multirow{2}{*}{ Micro1 } & $2.65 \pm 0.19$ & $9.57 \pm 1.15$ & $13.59 \pm 1.23$ \\
& $2.69 \pm 0.10$ & & \\
Micro2 & $1.09 \pm 0.02$ & $4.26 \pm 0.32$ & $25.13 \pm 0.99$ \\
& $1.13 \pm 0.04$ & & - \\
FLIPSS1 & $0.14 \pm 0.01$ & $0.52 \pm 0.05$ & - \\
& $0.13 \pm 0.004$ & & - \\
FLIPSS2 & $0.14 \pm 0.01$ & $0.50 \pm 0.02$ & \\
& $0.15 \pm 0.01$ & & \\
Reference & $0.08 \pm 0.02$ & $0.48 \pm 0.02$ & \\
& $0.09 \pm 0.01$ & & \\
\hline
\end{tabular}

\subsection{Wetting Properties of Ti6Al4V Surfaces}

The resulting contact angles on the structured surfaces and the references are shown in Table 3. Directly after laser treatment, a strong hydrophilic behavior can be observed, especially on FLIPPS1, whereas the contact angles of FLIPPS2 samples are in the same order of the contact angles of the references. This could be caused by the different impact of the chemical composition of the surface due to laser irradiation with lower pulse energy and lower line overlap. It is supposed that laser treatment and subsequent exposition to air leads to a formation of $\mathrm{TiO}_{2} / \mathrm{Al}_{2} \mathrm{O}_{3}$ and unsaturated chemical compounds on the surface; this is associated with a hydrophilic behavior and leads to hydrophilic surfaces [31]. This mechanism appears to depend on the laser fluence, or rather the irradiated energy on a spot seems to determine the level of oxygen on the surface [11]. Otherwise, the organization of the laser-induced periodic structures could have an important impact on the wettability, since the roughness Sa of FLIPPS1 and FLIPPS2 are nearly the same but do obviously lead to very different contact angles. As shown in Figure 1, FLIPPS structures on the FLIPPS2 sample are stronger pronounced and distributed more homogeneous that could result in a stronger hydrophobic behavior. Further experiments and chemical analyses (for instance, X-ray photoelectron spectroscopy (XPS)) can help further our understanding. Generally, a clear increase of the contact angle over time (1 and 7 days) on all laser-structured surfaces can be observed. Explanatory approaches are given in different studies. Kietzig et. al. [11] attribute the phenomenon to the fact that the amount of carbon on the surface increases due to the composition of $\mathrm{CO}_{2}$ and the accumulation of nonpolar carbon on the surface. 
Long et. al. [20] reported an absorption of organic compounds from the ambient atmosphere onto the oxide surface, which leads to a more hydrophobic surface. A strong change in wetting behavior is also observed on the structures Micro2. The sample Micro2 is highly covered with periodic nanostructures, as mentioned before, that can be seen as a reason for the higher increase of the contact angles compared to Micro1 over time. It is known that (microscale-) roughness leads to an increased hydrophobic behavior on already hydrophobic surfaces [32].

Table 3. Contact angle results after 1 and 7 days after laser treatment. The values are listed separately for each specimen.

\begin{tabular}{ccc}
\hline Sample & \multicolumn{2}{c}{ Contact Angle $\left(^{\circ}\right)$} \\
\hline \multirow{2}{*}{ Micro1 } & Storage Time 1 Day & Storage Time 7 Days \\
& $40.97 \pm 1.01$ & $73.53 \pm 1.14$ \\
Micro2 & $39.93 \pm 1.59$ & $79.60 \pm 2.5$ \\
& $40.30 \pm 3.16$ & $98.60 \pm 2.69$ \\
FLIPSS1 & $43.73 \pm 1.41$ & $100.13 \pm 4.42$ \\
& $18.80 \pm 5.16$ & $55.67 \pm 4.27$ \\
FLIPSS2 & $\sim 0$ & $59.70 \pm 3.75$ \\
& $78.00 \pm 1.94$ & $92.50 \pm 4.49$ \\
Reference & $75.17 \pm 1.35$ & $81.80 \pm 5.06$ \\
& $88.80 \pm 1.80$ & $83.73 \pm 2.09$ \\
& $89.37 \pm 1.91$ & $89.20 \pm 2.03$ \\
\hline
\end{tabular}

\subsection{Cellular Response}

The present in vitro study revealed no cytotoxic effect due to the femtosecond laser processes. The nano/micro textures produced by laser processes affected the adhesion, morphology, and growth of MG-63 cells. On Micro1 samples the cell morphology (Figure 2a,b) and the determined cell area (Figure 2c) were significantly different to the values on Micro2, FLIPPS1, FLIPPS2, and the reference. This cell behavior was independent of the surface wettability (after 1 and 7 days). In general, on the sample Micro1 fewer cells were detectable, embedded in deep cavities of the microstructure. It was also evident that the cells aligned with the structures due to the elevations and therefore could not spread out (Figure 2). Due to the laser micro texturing (Sa $>2.6 \mu \mathrm{m})$, some cells were in cavities or tried to spread along the structures. However, the cells could not completely align and spread well as they did on a smooth surface (FLIPSS1, FLIPPS2, and reference), but are limited and directed in their spreading and migration due to the size and shape of the microstructures. In these cases, the cells followed the structure of the surface and lined the elevations and craters. On all other surfaces more cells were observed. The osteoblasts on FLIPPS1 and FLIPPS2 as well as on the reference adhered tightly to the surfaces, and the spreading was superior. Cells on sample Micro2 were similar in morphology and spreading to reference and FLIPPS-structures, but with respect to their adhesion, it could be shown that they did not adhere tightly but rather spanned over sinusoids periodic microstructures.

The result with a reduced cell area on the stochastic pillar microstructure Micro1 is in agreement with another study which could show a significantly reduced cell spreading on regular pillar structures with sharp corners in the dimension of $5 \mu \mathrm{m}$ [15]. It is known that the structuring of separate areas of the metallic surfaces can be used to cause a desired and particular cell behavior [33,34]. 
Micro1

(a)
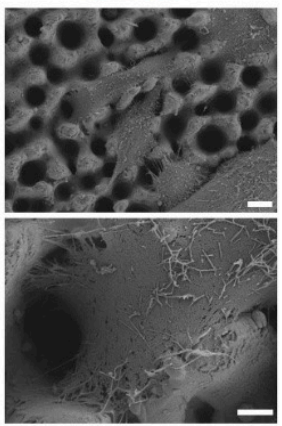

(b)
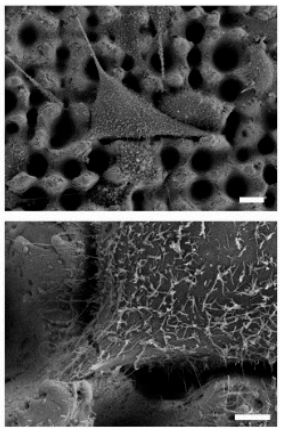

Micro2
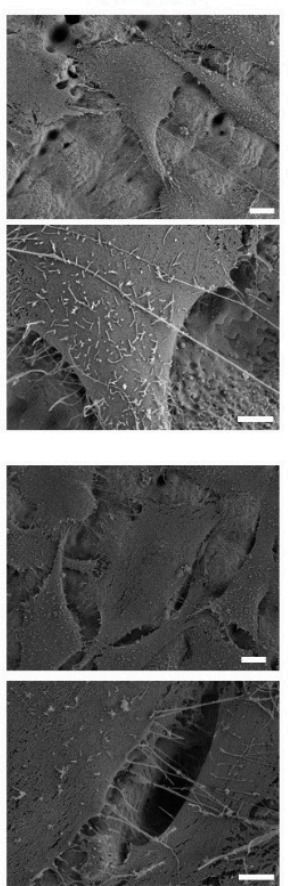

FLIPSS1
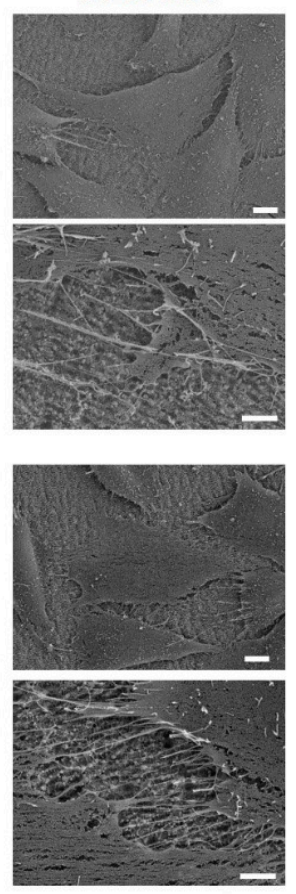

FLIPSS2
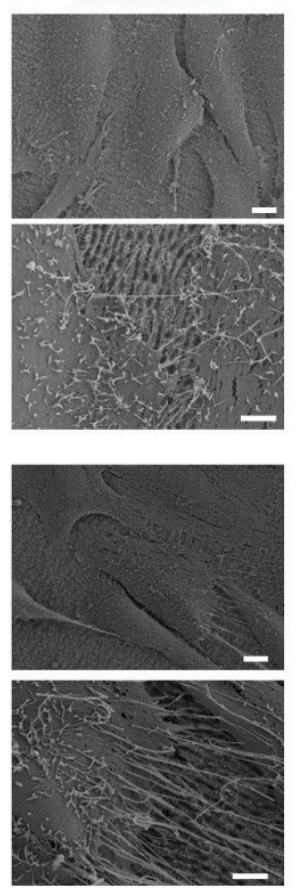

Reference
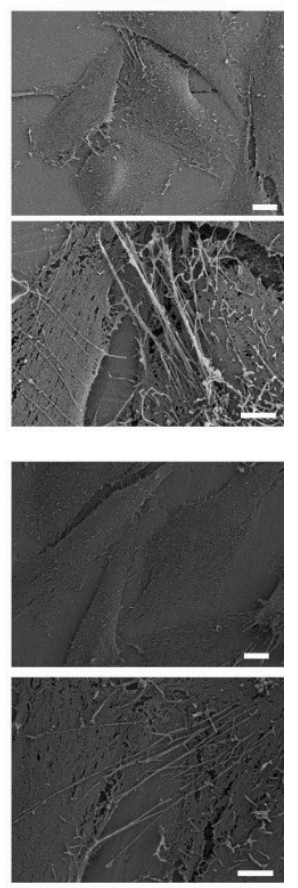

(c)

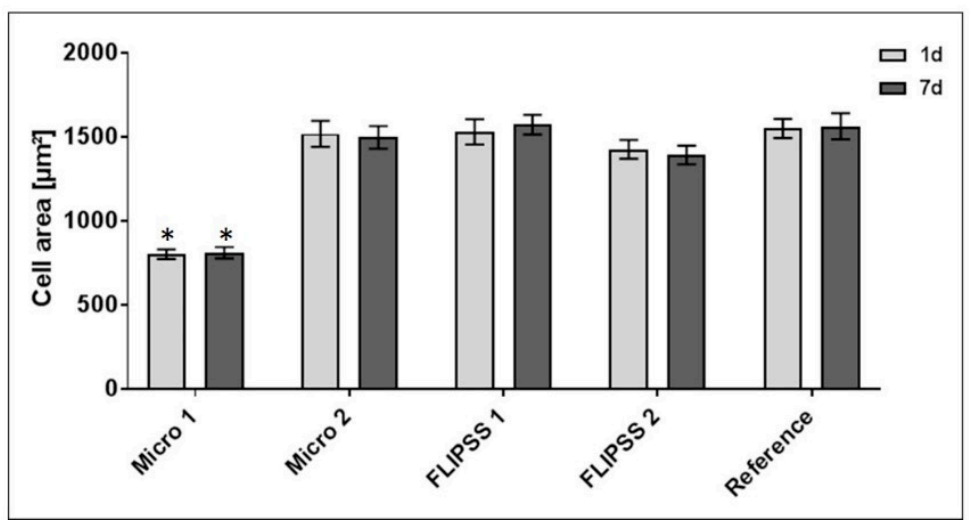

Figure 2. Cell morphology after $24 \mathrm{~h}$ on laser-structured samples (a) 1 day after laser process, and (b) 7 days after laser process (FE-SEM Merlin VP compact, scale bars above: $10 \mu \mathrm{m}$, below: $2 \mu \mathrm{m}$ ). (c) Cell area of osteoblasts on various nano/micro textured samples compared to planar reference (mean \pm s.e.m., Kruskal-Wallis test post hoc uncorrected Dunn's test, ${ }^{*} p<0.001, \mathrm{n}=40$ cells). Note that the cell growth was impaired on Micro1, which is independent of the wettability (see Table 3).

Another cell morphological aspect is the observation of the actin cytoskeleton. The CLSM images (Figure 3) confirmed the results of FE-SEM about the specific cell response on laser structures-the impaired cell growth on Micro1. The examination of actin cytoskeleton on Micro1 revealed only cortical actin fibers and short fragments within the cells. On the other laser-structured surfaces, cells formed a well-developed actin cytoskeleton with long filaments inside the cell.

On Micro2, due to the sinusoid periodic structures, actin was strongly cortically organized, and thin long filaments spanned the entire cell body. To supplement the qualitative confocal images (Figure 3), the actin filaments were quantified using the software FilaQuant $[25,26]$. The focus was on the total number of actin filaments, the length (total, max., mean), and the orientation of the cytoskeleton fibers. The quantification reveals a decrease of actin filament number of MG-63 cells on Micro1 compared to FLIPSS1 (7 days after laser processing), as well as FLIPSS2, and the reference (1 day after laser processing) due to the few cortical actin filaments (Table 4). Additionally, on micro textured samples (Micro1 \& Micro2) a reduced total filament length could be quantified. The actin filament distribution 
indicated no preferred orientation in the MG-63 cells on the samples $\left(0^{\circ}\right.$ : distinct one prefers direction; $28.65^{\circ}$ homogenous distribution). Thus, a contact guidance could not be determined here. The cell spreading, morphology, and actin organization on FLIPSS1 and FLIPSS2 were comparable with the plane reference. The differences in cell behavior between the laser-structured samples correlate well with the size and shape of the nano- or microstructures, but not with the wettability. The differences in wettability after the sample's storage time 1 and 7 days after laser treatment had no influence on the cell behavior as well.

(a)
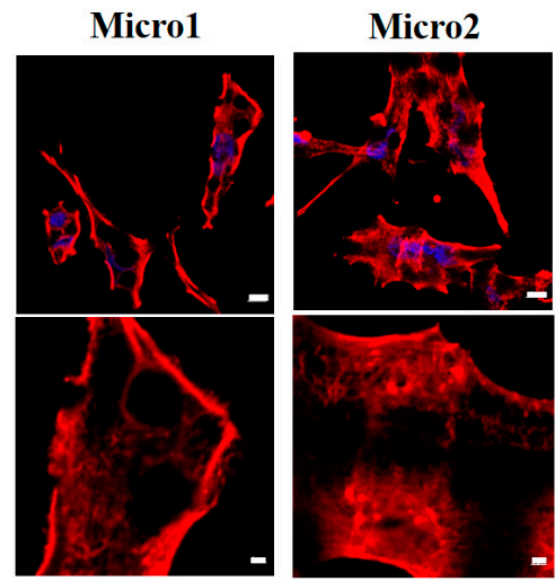

FLIPSS1
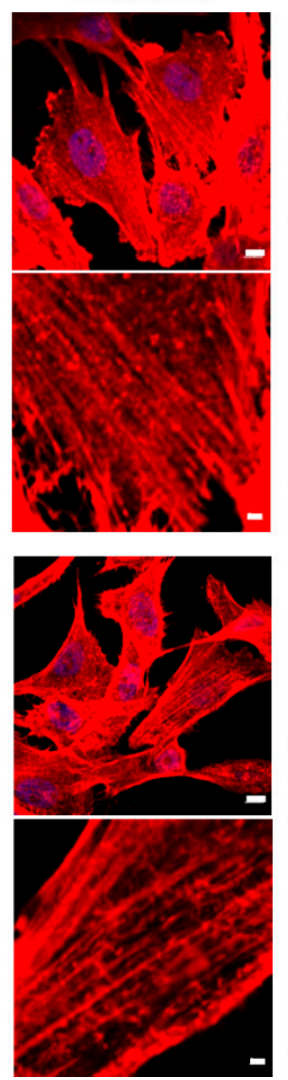

FLIPSS2
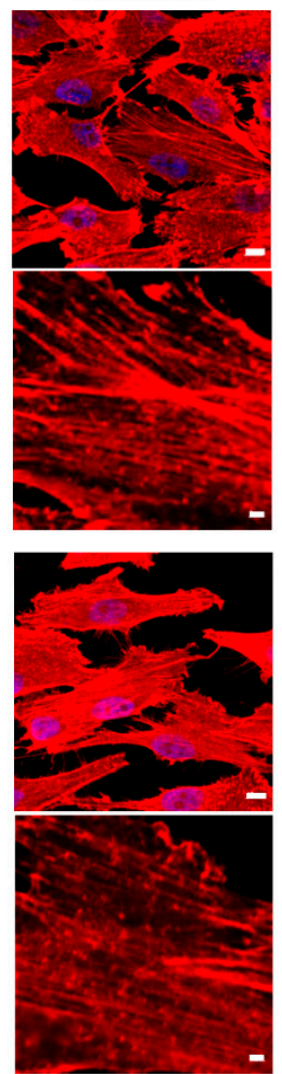

\section{Reference}
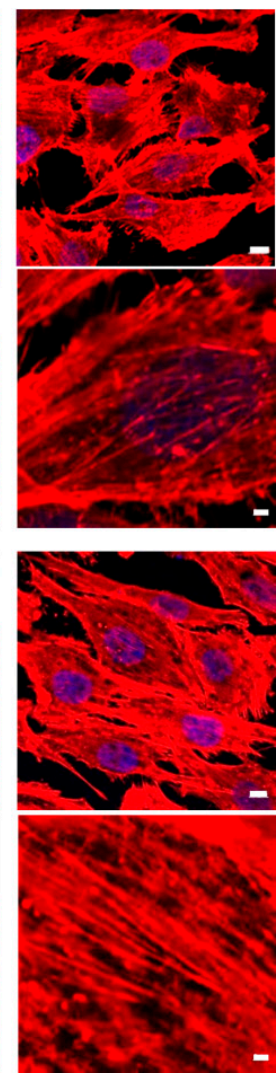

Figure 3. Organization of the actin cytoskeleton in MG-63 cells cultivated for $24 \mathrm{~h}$ on nano/micro textured samples. (a,b) 1 day after laser structuring, and (c,d) 7 days after laser structuring (LSM780, (a,c) zoom1, scale bars: $10 \mu \mathrm{m},(\mathbf{b}, \mathbf{d})$ zoom4, scale bars: $2 \mu \mathrm{m}$; red: actin, blue: nucleus). Note that the actin cytoskeleton was only cortically arranged or in short filaments inside the cells on Micro1, in contrast to all other samples, where cells exhibit long filaments through the cells.

The literature postulates that physico-chemical surface characteristics such as roughness and wettability influence cell adhesion, spreading, proliferation, and differentiation $[2,3,9,35]$. Raimbault et al. [21] pointed out that cell behavior is not necessarily positively modulated by hydrophilic surfaces, which is in accordance with our observations. Basically, we could not detect any cytotoxic effects on the femtosecond laser nano/micro textured samples. Kunzler et al. [34] could show that rat osteoblasts prefer rougher part on surface with gradually increasing surface roughness. The influence on osteoblast adhesion depended on the current size and depth dimensions as well as the roughness $(\mathrm{Sa})$. Cells on FLIPSS nanostructures with low roughness (Sa $<0.15 \mu \mathrm{m})$ showed a phenotype similar to the reference structure. Due to increased pulse energy, the microstructures Micro1 and Micro2 influence the cell response. Due to the sinusoids periodic microstructure (Micro2) only slight impairments in cell adhesion and actin organization were detectable, but the morphology and spread were unaffected and comparable to the nanostructures FLIPSS and reference. On Micro1 with pronounced pillar profile dimension (depth: $9.57 \pm 1.15 \mu \mathrm{m}$, width: $13.59 \pm 1.23 \mu \mathrm{m}$ ), a clear impact 
on cell adhesion and growth was evident. In the literature, an increase in the roughness is related to an improved cell adhesion and growth behavior [2,13,36-41]. However, with increasing roughness in a microscale area, the contact between the cells and the surface is reduced, thus impairing the cell adhesion [2]. Belaud et al. [36] demonstrated in their work that the combination of nanoscale and curved structures stimulates the adhesion and migration of stem cells. The group of Boyan et al. [37-40] showed that osteoblasts are sensitive to micro/nano structures and the surface roughness has a clear impact on signal protein synthesis, local factor production, and finally on cell proliferation and differentiation. Dowling et al. [41] demonstrated a reduced cell area at a high surface roughness ( $\mathrm{Ra}>2365 \mathrm{~nm}$ ) of plasma-treated polystyrene (PS) on MG-63 osteoblasts. In agreement with these findings, it was shown in the present study that a lower spreading potential of MG-63 cells occurs at higher surface roughness (Micro1, $\mathrm{Sa}>2.6 \mu \mathrm{m}$ ) compared to the reference $(\mathrm{Sa}<0.9 \mu \mathrm{m}$ ). However, there are inconsistencies between the present study and the findings of Dowling et al., especially concerning the effect of wetting on cell behavior. By comparing surface roughness/texture with the wettability, the present study showed that the surface wettability displayed no significant influence on cell morphology and spreading. Dowling et al. indicated the best cell adhesion at a contact angle value about $60^{\circ}$ (best $64^{\circ}$ ). Also, other groups could show that wettability of material surfaces seems to be optimal for cell responses, with a moderate hydrophilic water contact angles (WCA) region between $45-68^{\circ}[2,42,43]$.

Table 4. Quantitative analysis of the actin cytoskeleton organization was performed using the FilaQuant software (confocal images in Figure 3); ${ }^{*}($ mean \pm s.e.m.; ANOVA post hoc Bonferroni, $\mathrm{n}=10$ cells; $n . s$. between 1 day vs 7 days laser process).

\begin{tabular}{cccccc}
\hline Sample & $\begin{array}{c}\text { Actin Filament } \\
\text { Number }\end{array}$ & $\begin{array}{c}\text { Total Filament } \\
\text { Length }(\mu \mathrm{m})\end{array}$ & $\begin{array}{c}\text { Mean Filament } \\
\text { Length }(\mu \mathrm{m})\end{array}$ & $\begin{array}{c}\text { Max. Filament } \\
\text { Length }(\mu \mathrm{m})\end{array}$ & $\begin{array}{c}\text { Orientation } \\
\text { Dispersion }\left({ }^{\circ}\right)\end{array}$ \\
\hline \multicolumn{7}{c}{ Storage time 1 day } \\
\hline Micro1 & $10.9 \pm 2.9^{\mathrm{a}, \mathrm{b}, \mathrm{c}}$ & $92.5 \pm 38.5^{\mathrm{a}}$ & $4.5 \pm 0.7^{\mathrm{a}}$ & $23.4 \pm 9.4$ & $17.5 \pm 1.7$ \\
Micro2 & $20.2 \pm 4.3$ & $105.4 \pm 21.3^{\mathrm{a}}$ & $5.6 \pm 1.1^{\mathrm{a}}$ & $18.1 \pm 6.6$ & $22.8 \pm 2.2$ \\
FLIPSS1 & $56.2 \pm 14,6$ & $387.5 \pm 120.3$ & $8.1 \pm 1.1$ & $33.5 \pm 7.1$ & $22.5 \pm 2.0$ \\
FLIPSS2 & $49 \pm 8.9$ & $359.2 \pm 43.9$ & $7.8 \pm 1.4$ & $39.4 \pm 8.3$ & $21.8 \pm 1.3$ \\
Reference & $49.5 \pm 8.6$ & $552.1 \pm 89.5$ & $10.4 \pm 0.2$ & $52.5 \pm 10.7$ & $21.5 \pm 1.7$ \\
\hline \multicolumn{7}{c}{ Storage time 7 days } \\
\hline Micro1 & $18.1 \pm 3.2^{\mathrm{b}}$ & $105.5 \pm 24.7^{\mathrm{a}, \mathrm{c}}$ & $3.7 \pm 1.4$ & $17.0 \pm 5.6$ & $24.5 \pm 1.0$ \\
Micro2 & $21.7 \pm 2.6$ & $104.4 \pm 11.9^{\mathrm{a}, \mathrm{c}}$ & $3.6 \pm 1.2$ & $15.5 \pm 4.0$ & $22.0 \pm 1.7$ \\
FLIPSS1 & $40.4 \pm 4.1$ & $213.7 \pm 25.8$ & $7.4 \pm 4.3$ & $40.3 \pm 7.1$ & $21.7 \pm 2.1$ \\
FLIPSS2 & $35.8 \pm 5.1$ & $427.5 \pm 43.9$ & $6.4 \pm 3.7$ & $46.5 \pm 6.1$ & $20.4 \pm 1.3$ \\
Reference & $35.7 \pm 7.4$ & $552.1 \pm 89.5$ & $6.7 \pm 3.9$ & $47.4 \pm 13.3$ & $22.4 \pm 2.2$ \\
\hline \multicolumn{7}{c}{${ }^{*}{ }^{*} p<0.05$ vs. Reference; ${ }^{\mathrm{b}}:{ }^{*} p<0.05$ vs. FLIPSS1; ${ }^{\mathrm{c}}:{ }^{*} p<0.05$ vs. FLIPSS2. }
\end{tabular}

Here, the osteoblast cell area was impaired on Micro1 due to the micro texture and not due to wettability. Another aspect of surface characterization needs to be explored in the next study, as it is known from the literature that surface energy affects the cellular response. Gentleman et al. [44] described the influence of surface free energy as an important part in osteoblast interaction at the interface to materials. Also, Hallab et al. [45] indicated that the surface energy may be more important for fibroblast adhesion than surface roughness. Moerke et al. [46] pointed out that a positive surface charge on microgrooves seemed to be an important parameter for the cellular outcome.

In the end, the femtosecond laser nano/micro texture appears to be a good tool for producing topographically functionalized material surfaces to guide the adhesion and growth of bone cells [47]. Further studies could be able to show that the laser structuring of Ti6Al4V samples, which, apart from well suited to the mechanical, (electro) chemical, and biological properties of the material, can control the in vitro cellular behavior [13] and increase the osteointegration and consequently the durability of implants in vivo [48]. Furthermore, the first step in cell adhesion mechanism-protein 
adsorption-should be investigated. A possible reason for the equal cell adhesion on uncoated laser textures, after 1 and 7 days with different wettabilities, is the similar adsorption of protein layer on these surfaces [49]. Hasan et al. [50-52] showed that the protein absorption is a function of the hydrophobicity of surfaces that were chemically modified via salinization. It is assumed that the presence of FBS (fetal bovine serum) on a surface affects the cell adhesion. The effect of femtosecond laser structuring on protein adsorption and cell adhesion could be also be investigated in further studies.

\section{Conclusions}

Human MG-63 osteoblast growth is dependent on the nano/micro textures of femtosecond laser-structured titanium alloy. Microstructures with a pronounced pillar micro-profile (Micro1) showed a clear impairment on cell adhesion and spreading. The cellular response correlates well with the topology (size and shape) of the nano/micro texture, but not with the wettability. Laser processes are well suited for roughening titanium surfaces and thus modifying biomaterials in regenerative medicine.

Author Contributions: All authors conceived and designed the experiments. G.S. and U.D. manufactured the specimens and analyzed the surface properties and the wetting behavior. S.S. performed the experiments with MG-63 cells and evaluated the data with support of J.B.N.; G.S. and S.S. wrote the paper; J.B.N. and H.S. reviewed and edited the paper.

Funding: This research was funded by the Federal Ministry of Education and Research (funding code: 03WKCU6B; Innovative Regional Growth Cores "MikroLas" which is part of the initiative "Entrepreneurial Regions"- "The BMBF Innovation Initiative for the New German Länder"). This work was supported by the German Research Foundation (DFG, grant number 1270/1 collaborative research center "ELAINE"). We also acknowledge financial support by the DFG and the University Rostock within the funding program Open Access Publishing.

Acknowledgments: The authors thank M. Frank and A. Springer ("Elektronenmikroskopisches Zentrum", Rostock) for SEM-Imaging.

Conflicts of Interest: The authors declare no conflict of interest. The funders had no role in the design of the study; in the collection, analyses, or interpretation of data; in the writing of the manuscript, or in the decision to publish the results.

\section{References}

1. Chen, S.; Guo, Y.; Liu, R.; Wu, S.; Fang, J.; Huang, B.; Li, Z.; Chen, Z.; Chen, Z. Tuning surface properties of bone biomaterials to manipulate osteoblastic cell adhesion and the signaling pathways for the enhancement of early osseointegration. Colloids Surf. B Biointerfaces 2018, 164, 58-69. [CrossRef] [PubMed]

2. Anselme, K.; Ponche, A.; Bigerelle, M. Relative influence of surface topography and surface chemistry on cell response to bone implant materials. Part 2: Biological aspects. Proc. Inst. Mech. Eng. H 2010, 224, 1487-1507. [CrossRef] [PubMed]

3. Rychly, J.; Nebe, B. Cell-material interaction. BioNanoMaterials 2013, 14. [CrossRef]

4. Zhao, C.; Cao, P.; Ji, W.; Han, P.; Zhang, J.; Zhang, F.; Jiang, Y.; Zhang, X. Hierarchical titanium surface textures affect osteoblastic functions. J. Biomed. Mater. Res. A 2011, 99, 666-675. [CrossRef] [PubMed]

5. Lofti, M.; Nejib, M.; Naceur, M. Cell Adhesion to Biomaterials: Concept of Biocompatibility. In Advances in Biomaterials Science and Biomedical Applications; Pignatello, R., Ed.; IntechOpen: London, UK, 2013; Chapter 8. [CrossRef]

6. Geetha, M.; Singh, A.K.; Asokamani, R.; Gogia, A.K. Ti based biomaterials, the ultimate choice for orthopaedic implants-A review. Prog. Mater. Sci. 2009, 54, 397-425. [CrossRef]

7. Brunette, D.; Tengvall, P.; Textor, M.; Thomsen, P. Titanium in Medicine: Material Science, Surface Science, Engineering, Biological Responses and Medical Applications; Springer Science \& Business Media: Berlin/Heidelberg, Germany, 2001. [CrossRef]

8. Jones, F. Teeth and bones: Applications of surface science to dental materials and related biomaterials. Surf. Sci. Rep. 2001, 42, 75-205. [CrossRef]

9. Ponsonnet, L.; Reybier, K.; Jaffrezic, N.; Comte, V.; Lagneau, C.; Lissac, M.; Martelet, C. Relationship between surface properties (roughness, wettability) of titanium and titanium alloys and cell behaviour. Mater. Sci. Eng. C 2003, 23, 551-560. [CrossRef] 
10. Cunha, A.; Serro, A.P.; Oliveira, V.; Almeida, A.; Vilar, R.; Durrieu, M.-C. Wetting behaviour of femtosecond laser textured Ti-6Al-4V surfaces. Appl. Surf. Sci. 2013, 265, 688-696. [CrossRef]

11. Kietzig, A.-M.; Hatzikiriakos, S.G.; Englezos, P. Patterned superhydrophobic metallic surfaces. Langmuir 2009, 25, 4821-4827. [CrossRef]

12. Jagdheesh, R.; Pathiraj, B.; Karatay, E.; Römer, G.R.B.E.; Huis in't Veld, A.J. Laser-induced nanoscale superhydrophobic structures on metal surfaces. Langmuir 2011, 27, 8464-8469. [CrossRef]

13. Cunha, A.; Oliveira, V.; Serro, A.P.; Zouani, O.E.-F.; Almeida, A.; Durrieu, M.-C.; Vilar, R. Ultrafast laser texturing of Ti-6Al-4V surfaces for biomedical applications. In Proceedings of the International Congress on Applications of Lasers \& Electro-Optics, Miami, FL, USA, 6-10 October 2013; Laser Institute of America: Orlando, FL, USA, 2013; pp. 910-918. [CrossRef]

14. Miller, P.R.; Aggarwal, R.; Doraiswamy, A.; Lin, Y.J.; Lee, Y.-S.; Narayan, R.J. Laser micromachining for biomedical applications. JOM 2009, 61, 35-40. [CrossRef]

15. Staehlke, S.; Koertge, A.; Nebe, B. Intracellular calcium dynamics in dependence on topographical features of titanium. Biomaterials 2015, 46, 48-57. [CrossRef] [PubMed]

16. Chen, P.; Aso, T.; Sasaki, R.; Ashida, M.; Tsutsumi, Y.; Doi, H.; Hanawa, T. Adhesion and differentiation behaviors of mesenchymal stem cells on titanium with micrometer and nanometer-scale grid patterns produced by femtosecond laser irradiation. J. Biomed. Mater. Res. A 2018, 106, 2735-2743. [CrossRef] [PubMed]

17. Brånemark, R.; Emanuelsson, L.; Palmquist, A.; Thomsen, P. Bone response to laser-induced micro- and nano-size titanium surface features. Nanomedicine 2011, 7, 220-227. [CrossRef] [PubMed]

18. Cunha, A.; Elie, A.-M.; Plawinski, L.; Serro, A.P.; Botelho do Rego, A.M.; Almeida, A.; Urdaci, M.C.; Durrieu, M.-C.; Vilar, R. Femtosecond laser surface texturing of titanium as a method to reduce the adhesion of Staphylococcus aureus and biofilm formation. Appl. Surf. Sci. 2016, 360, 485-493. [CrossRef]

19. Fadeeva, E.; Truong, V.K.; Stiesch, M.; Chichkov, B.N.; Crawford, R.J.; Wang, J.; Ivanova, E.P. Bacterial retention on superhydrophobic titanium surfaces fabricated by femtosecond laser ablation. Langmuir 2011, 27, 3012-3019. [CrossRef] [PubMed]

20. Long, J.; Zhong, M.; Zhang, H.; Fan, P. Superhydrophilicity to superhydrophobicity transition of picosecond laser microstructured aluminum in ambient air. J. Colloid Interface Sci. 2015, 441, 1-9. [CrossRef]

21. Raimbault, O.; Benayoun, S.; Anselme, K.; Mauclair, C.; Bourgade, T.; Kietzig, A.-M.; Girard-Lauriault, P.-L.; Valette, S.; Donnet, C. The effects of femtosecond laser-textured Ti-6Al-4V on wettability and cell response. Mater. Sci. Eng. C Mater. Biol. Appl. 2016, 69, 311-320. [CrossRef]

22. SAE International. AMS4911: Titanium Alloy, Sheet, Strip, and Plate, 6Al - 4V, Annealed. Available online: https://saemobilus.sae.org/content/AMS4911/ (accessed on 8 July 2019).

23. Beuth Verlag GmbH. WL 3.7164-1: Aerospace; titanium alloy with approx. 6Al-4V; sheet and plate. Available online: https://www.beuth.de/de/norm/w1-3-7164-1/1616956 (accessed on 8 July 2019).

24. Staehlke, S.; Rebl, H.; Nebe, B. Phenotypic stability of the human MG-63 osteoblastic cell line at different passages. Cell Biol. Int. 2019, 43, 22-32. [CrossRef]

25. Matschegewski, C.; Staehlke, S.; Birkholz, H.; Lange, R.; Beck, U.; Engel, K.; Nebe, J. Automatic actin filament quantification of osteoblasts and their morphometric analysis on microtextured silicon-titanium arrays. Materials 2012, 5, 1176-1195. [CrossRef]

26. Matschegewski, C.; Birkholz, H.; Staehlke, S.; Loeffler, R.; Kern, P.D.; Engel, K.; Nebe, J.B. Quantitative analysis of the cellular actin cytoskeleton on geometrically designed surface topography. Mater. Sci. Forum 2012, 706-709, 543-548. [CrossRef]

27. Vorobyev, A.Y.; Guo, C. Direct femtosecond laser surface nano/microstructuring and its applications. Laser Photonics Rev. 2013, 7, 385-407. [CrossRef]

28. Sánchez, F.; Morenza, J.L.; Aguiar, R.; Delgado, J.C.; Varela, M. Dynamics of the hydrodynamical growth of columns on silicon exposed to ArF excimer-laser irradiation. Appl. Phys. A Mater. Sci. Process. 1998, 66, 83-86. [CrossRef]

29. Zuhlke, C.A.; Anderson, T.P.; Alexander, D.R. Understanding the formation of self-organized micro/nanostructures on metal surfaces from femtosecond laser ablation using stop-motion SEM imaging. In Proceedings of the Laser-Based Micro- and Nanoprocessing VIII, San Francisco, CA, USA, 1-6 February 2014; Klotzbach, U., Washio, K., Arnold, C.B., Eds.; SPIE: Bellingham, WA, USA, 2014; Volume 89680C. 
30. Oliveira, V.; Ausset, S.; Vilar, R. Surface micro/nanostructuring of titanium under stationary and non-stationary femtosecond laser irradiation. Appl. Surf. Sci. 2009, 255, 7556-7560. [CrossRef]

31. Cardoso, J.T.; Garcia-Girón, A.; Romano, J.M.; Huerta-Murillo, D.; Jagdheesh, R.; Walker, M.; Dimov, S.S.; Ocaña, J.L. Influence of ambient conditions on the evolution of wettability properties of an IR-, ns-laser textured aluminium alloy. RSC Adv. 2017, 7, 39617-39627. [CrossRef]

32. Cassie, A.B.D.; Baxter, S. Wettability of porous surfaces. Trans. Faraday Soc. 1944, 40, 546. [CrossRef]

33. Curtis, A.; Wilkinson, C. Topographical control of cells. Biomaterials 1997, 18, 1573-1583. [CrossRef]

34. Kunzler, T.P.; Drobek, T.; Schuler, M.; Spencer, N.D. Systematic study of osteoblast and fibroblast response to roughness by means of surface-morphology gradients. Biomaterials 2007, 28, 2175-2182. [CrossRef]

35. Oliveira, S.M.; Alves, N.M.; Mano, J.F. Cell interactions with superhydrophilic and superhydrophobic surfaces. J. Adhes. Sci. Technol. 2012, 28, 843-863. [CrossRef]

36. Belaud, V.; Petithory, T.; Ponche, A.; Mauclair, C.; Donnet, C.; Pieuchot, L.; Benayoun, S.; Anselme, K. Influence of multiscale and curved structures on the migration of stem cells. Biointerphases 2018, 13, $06 \mathrm{D} 408$. [CrossRef]

37. Kieswetter, K.; Schwartz, Z.; Hummert, T.W.; Cochran, D.L.; Simpson, J.; Dean, D.D.; Boyan, B.D. Surface roughness modulates the local production of growth factors and cytokines by osteoblast-like MG-63 cells. J. Biomed. Mater. Res. 1996, 32, 55-63. [CrossRef]

38. Olivares-Navarrete, R.; Hyzy, S.L.; Berg, M.E.; Schneider, J.M.; Hotchkiss, K.; Schwartz, Z.; Boyan, B.D. Osteoblast lineage cells can discriminate microscale topographic features on titanium-aluminum-vanadium surfaces. Ann. Biomed. Eng. 2014, 42, 2551-2561. [CrossRef] [PubMed]

39. Lincks, J.; Boyan, B.D.; Blanchard, C.R.; Lohmann, C.H.; Liu, Y.; Cochran, D.L.; Dean, D.D.; Schwartz, Z. Response of MG63 osteoblast-like cells to titanium and titanium alloy is dependent on surface roughness and composition. Biomaterials 1998, 19, 2219-2232. [CrossRef]

40. Boyan, B.D.; Lossdörfer, S.; Wang, L.; Zhao, G.; Lohmann, C.H.; Cochran, D.L.; Schwartz, Z. Osteoblasts generate an osteogenic microenvironment when grown on surfaces with rough microtopographies. Cell Mater. 2003, 24, 22-27. [CrossRef]

41. Dowling, D.P.; Miller, I.S.; Ardhaoui, M.; Gallagher, W.M. Effect of surface wettability and topography on the adhesion of osteosarcoma cells on plasma-modified polystyrene. J. Biomater. Appl. 2011, 26, 327-347. [CrossRef] [PubMed]

42. Van Wachem, P.B.; Beugeling, T.; Feijen, J.; Bantjes, A.; Detmers, J.P.; van Aken, W.G. Interaction of cultured human endothelial cells with polymeric surfaces of different wettabilities. Biomaterials 1985, 6, 403-408. [CrossRef]

43. Lim, J.Y.; Liu, X.; Vogler, E.A.; Donahue, H.J. Systematic variation in osteoblast adhesion and phenotype with substratum surface characteristics. J. Biomed. Mater. Res. A 2004, 68, 504-512. [CrossRef] [PubMed]

44. Gentleman, M.M.; Gentleman, E. The role of surface free energy in osteoblast-biomaterial interactions. Int. Mater. Rev. 2014, 59, 417-429. [CrossRef]

45. Hallab, N.J.; Bundy, K.J.; O'Connor, K.; Moses, R.L.; Jacobs, J.J. Evaluation of metallic and polymeric biomaterial surface energy and surface roughness characteristics for directed cell adhesion. Tissue Eng. 2001, 7, 55-71. [CrossRef]

46. Moerke, C.; Rebl, H.; Finke, B.; Dubs, M.; Nestler, P.; Airoudj, A.; Roucoules, V.; Schnabelrauch, M.; Koertge, A.; Anselme, K.; et al. Abrogated cell contact guidance on amino-functionalized micro-grooves. ACS Appl. Mater. Interfaces 2017, 9, 10461-10471. [CrossRef]

47. Fadeeva, E.; Deiwick, A.; Chichkov, B.; Schlie-Wolter, S. Impact of laser-structured biomaterial interfaces on guided cell responses. Interface Focus 2014, 4, 20130048. [CrossRef] [PubMed]

48. Coathup, M.J.; Blunn, G.W.; Mirhosseini, N.; Erskine, K.; Liu, Z.; Garrod, D.R.; Li, L. Controlled laser texturing of titanium results in reliable osteointegration. J. Orthop. Res. 2017, 35, 820-828. [CrossRef] [PubMed]

49. Anselme, K. Osteoblast adhesion on biomaterials. Biomaterials 2000, 21, 667-681. [CrossRef]

50. Hasan, A.; Pattanayek, S.K.; Pandey, L.M. Effect of Functional Groups of Self-Assembled Monolayers on Protein Adsorption and Initial Cell Adhesion. ACS Biomater. Sci. Eng. 2018, 4, 3224-3233. [CrossRef] 
51. Hasan, A.; Waibhaw, G.; Pandey, L.M. Conformational and Organizational Insights into Serum Proteins during Competitive Adsorption on Self-Assembled Monolayers. Langmuir 2018, 34, 8178-8194. [CrossRef] [PubMed]

52. Hasan, A.; Saxena, V.; Pandey, L.M. Surface Functionalization of Ti6Al4V via Self-assembled Monolayers for Improved Protein Adsorption and Fibroblast Adhesion. Langmuir 2018, 34, 3494-3506. [CrossRef] [PubMed]

(C) 2019 by the authors. Licensee MDPI, Basel, Switzerland. This article is an open access article distributed under the terms and conditions of the Creative Commons Attribution (CC BY) license (http://creativecommons.org/licenses/by/4.0/). 